\title{
PENDIDIKAN KESEHATAN DAN APLIKASINYA DI SD/MI
}

\section{Bintoro Widodo ${ }^{1}$}

\begin{abstract}
Healtheducation is part of the overall efforts of health (promotive, preventive, curative and rehabilitative) which focuses on efforts to increase healthy living behaviors. In the concept of health education is an effort to influence/ encourage others (individuals, groups and communities) in order to behave in a healthy life. Operationally in health education are all activities to provide / improve the knowledge, attitudes and practices of communities in maintaining and improving health. Health education is synonymous with health counseling because both of them are expected behavior changeoriented which is healthy behaviors, so it has the ability to recognize health problems himself, his family and his group in improving health. Health education is a part of health promotion is a process to improve the ability of communities to maintain and improve their health and not just relate themselves to increase the knowledge, attitudes and practices of health, but also increase or improve the environment (both physical and non-physical) in order to maintain and improve health.
\end{abstract}

Keywords: health education, school, environment.

\section{A. Latar Belakang}

Pendidikan merupakan segala upaya yang direncanakan untuk mempengaruhi orang lain baik individu, kelompok maupun masyarakat sehingga mereka melakukan apa yang diharapkan oleh pelaku pendidikan. Pendidikan kesehatan mempunyai peran yang penting dalam mewujudkan manusia yang sehat. Kesehatan merupakan dambaan setiap manusia. Manusia yang sehat dapat melakukan aktivitasnya dengan optimal. Pendidikan kesehatan dapat diberikan melalui pendidikan formal maupun non formal. Di lingkungan sekolah pendidikan kesehatan dapat dimasukan dalam mata pelajaran pendidikan jasmani olahraga dan kesehatan atau mata pelajaran lainnya yang relevan. Selain itu, dapat dilakukannya melalui program usaha kesehatan sekolah. Pendidikan kesehatan penting untuk menunjang program-program kesehatan yang lain.

1 Dosen PGMI Fakultas Ilmu Tarbiyah dan Keguruan UIN Maliki Malang 
Istilah pendidikan kesehatan telah dirumuskan oleh para ahli pendidikan kesehatan dalam berbagai pengertian, tergantung pada sudut pandang masing-masing.

Pendidikan kesehatan merupakan bagian dari keseluruhan upaya kesehatan (promotif, prefentif, kuratif, dan rehabilitatif) yang menitikberatkan pada upaya untuk meningkatkan prilaku hidup sehat. Secara konsep pendidikan kesehatan merupakan upaya mempengaruhi/mengajak orang lain (individu, kelompok , dan masyarakat) agar berprilaku hidup sehat. Secara operasional pendidikan kesehatan adalah semua kegiatan untuk memberikan/ meningkatkan pengetahuan, sikap dan praktek masyaarakat dalam memelihara dan meningkatkan kesehatannya (Notoatmojo, 2003). Pendidikan kesehatan identik dengan penyuluhan kesehatan karena keduannya berorientasi pada perubahan perilaku yang diharapkan, yaitu prilaku sehat, sehingga mempunyai kemampuan mengenal masalah kesehatan dirinya, keluarga dan kelompoknya dalam meningkatkan kesehatannya. Pendidikan kesehatan merupakan bagian dari promosi kesehatan, yaitu suatu proses untuk meningkatkan kemampuan masyarakat dalam memelihara dan meningkatkan kesehatannya dan tidak hanya mengaitkan diri pada peningkatan pengetahuan, sikap dan praktek kesehatan saja, tetapi juga meningkatkan atau memperbaiki lingkungan (baik fisik maupun non fisik) dalam rangka memelihara dan meningkatkan kesehatan mereka (notoatmodjo, 2007).

Menurut Nyswander yang di kutip Notoatmodjo (1997), menyatakan bahwa pendidikan kesehatan adalah proses perubahan perilaku yang dinamis bukan proses pemindahan materi dari seseorang ke orang lain dan bukan pula seperangkat prosedur. Hal itu dapat dilihat dari definisi yang dia kemukakan, yaitu: pendidikan kesehatan adalah suatu proses perubahan pada diri seseorang yang dihubungkan dengan pencapaian tujuan kesehatan individu dan masyarakat. Pendidikan kesehatan tidak dapat diberikan kepada seseorang atau orang lain, bukan seperangkat prosedur yang harus dilaksanakan atau suatu produk yang harus dicapai, tetapi sesungguhnya merupakan suatu proses perkembangan yang berubah secara dinamis, yang di dalamnya seseorang menerima atau menolak informasi, sikap maupun praktek baru, yang berhubungan dengan tujuan hidup sehat. Menurut Committee President on Health Education 
yang di kutip oleh Notoatmodjo (1997), pendidikan kesehatan adalah proses yang menjembatani kesejangan antara informasi kesehatan dan praktek kesehatan, yang memotivasi seseorang untuk memperoleh informasi dan membuat sesuatu sehingga dapat menjaga dirinya menjadi lebih sehat dengan menghindari kebiasaan yang buruk dan membentuk kebiasaan yang menguntungkan kesehatan. Pendidikan kesehatan menurut Wahid dkk, (2007) adalah proses perubahan perilaku yang dinamis, di mana perubahan tersebut bukan sekedar proses trasfer materi/teori dari seseorang ke orang lain dan bukan pula seperangkat prosedur, akan tetapi perubahan tersebut terjadi adanya kesadaran dari dalam diri individu, kelompok atau masyarakat sendiri. Dari beberapa pendapat di atas dapat disimpulkan bahwa pendidikan kesehatan adalah proses membantu seseorang, dengan bertindak secara sendiri-sendiri ataupun secara kolektif, untuk membuat keputusan berdasarkan pengetahuan mengenai hal-hal yang mempengaruhi kesehatan pribadinya dan orang lain untuk meningkatkan kemampuan masyarakat dalam memelihara dan meningkatkan kesehatannya dan tidak hanya mengaitkan diri pada peningkatan pengetahuan, sikap dan pratik kesehatan saja, tetapi juga meningkatkan atau memperbaiki lingkungan (baik fisik maupun non fisik) dalam rangka memelihara dan meningkatkan kesehatan dengan penuh kesadaran.

\section{B. Tujuan Pendidikan Kesehatan}

Tujuan pendidikan kesehatan merupakan domain yang akan di tuju dari pendidikan kesehatan. Tujuan pendidikan kesehatan adalah mengubah perilaku dari yang merugikan kesehatan atau tidak sesuai dengan norma kesehatan ke arah tingkah laku yang menguntungkan kesehatan atau norma yang sesuai dengan kesehatan. Pendidikan kesehatan memiliki beberapa tujuan antara lain:

1. Tercapainya perubahan perilaku individu, keluarga, dan masyarakat dalam membina dan memelihara perilaku sehat dan lingkungan sehat, serta peran aktif dalam upaya mewujudkan derajat kesehatan yang optimal.

2. Terbentuknya perilaku sehat pada individu, keluarga, dan masyarakat yang sesuai dengan konsep hidup sehat baik fisik, mental maupun sosial sehingga dapat menurunkan angka kesakitan dan kematian. 
3. Menurut $\mathrm{WHO}$, tujuan penyuluhan kesehatan adalah untuk mengubah perilaku perseorangan dan atau masyarakat dalam bidang kesehatan (Effendy, 1998).

Tujuan utama pendidikan kesehatan adalah agar orang mampu menerapkan masalah dan kebutuhan mereka sendiri, maupun memahami apa yang dapat mereka lakukan terhadap masalahnya, dengan sumber daya yang ada pada mereka ditambah dengan dukungan dariluar, dan mampu memutuskan kegiatan yang tepatguna untuk meningkatkan taraf hidup sehat dan kesejahteraan masyarakat. Menurut Undang-undang Kesehatan No. 23 Tahun 1992 dan WHO, tujuan pendidikan kesehatan adalah meningkatkan kemampuan masyarakat untuk memelihara dan meningkatkan derajad kesehatan; baik secara fisik, menta,l maupun sosialnya, sehingga produktif secara ekonomi maupun sosial, pendidikan kesehatan di semua program kesehatan; baik pemberantasan penyakit menular, sanitasi lingkungan, gizi masyarakat, pelayanan kesehatan, maupun program kesehatan lainnya (Wahid, 2007). Tujuan pendidikan kesehatan adalah untuk mengubah pemahaman individu, kelompok dan masyarakat di bidang kesehatan agar menjadikan kesehatan sebagai sesuatu yang bernilai mandiri dalam mencapai tujuan hidup sehat, serta dapat menggunakan fasilitas pelayanan kesehatan yang ada dengan tepat dan sesuai (Herawati dkk, 2001).

Jadi tujuan pendidikan kesehatan adalah untuk memperoleh pengetahuan dan pemahaman akan pentingnya kesehatan untuk tercapainya perilaku kesehatan sehingga dapat meningkatkan derajatkesehatan fisik, mental, dan sosial, sehingga produktif secara ekonomi maupun sosial untuk mengubah perilaku masyarakat yang tidak sehat menjadi sehat. Secara khusus tujuan pendidikan kesehatan dapat dijabarkan sebagai berikut: 1. Meningkatkan kemampuan masyarakat untuk memelihara dan meningkatkan derajat kesehatan, 2. Menjadikan kesehatan sebagai kebutuhan utama di masyarakat, 3. Meningkatkan pengembangan dan penggunaan sarana dan prasarana kesehatan secara tepat, 4. Meningkatkan tanggung jawab dan kesadaran masyarakat terhadap kesehatan, 5. Memiliki daya tangkal atau pemberantasan terhadap penularan penyakit, 6. Memiliki kemauan dan kemampuan masyarakat terkait dengan promotif (peningkatan kesehatan), preventif (pencegahan), kuratif dan rehabilitative (penyembuhan dan pemulihan). 


\section{Ruang lingkup Pendidikan Kesehatan}

Ruang lingkup pendidikan kesehatan dapat dilihat dari berbagai dimensi, antara lain dimensi sasaran pendidikan, tempat pelayanan pendidikan kesehatan, dan tingkat pelayanan kesehatan. Berdasarkan dimensi sasaran pendidikan kesehatan dibagi menjadi: 1. Pendidikan kesehatan individu dengan sasaran individu, 2. Pendidikan kesehatan kelompok dengan sasaran kelompok, 3. Pendidikan kesehatan masyarakat dengan sasaran masyarakat.

Berdasarkan dimensi pelaksanaannya, pendidikan kesehatan dibagi menjadi: 1. Pendidkan kesehatan di sekolah dengan sasaran murid atau siswa, yang pelaksanaannya diintegrasikan dalam Usaha Kesehatan Sekolah (UKS). Implementasi yang lain dapat dilakukan pula melalui kegiatan Palang Merah Remaja (PMR), bahkan dalam kurikulum juga dimasukkan dalam mata pelajaran tertentu misalnya saja mata pelajaran pendidikan jasmani olahraga dan kesehatan, 2. Pendidikan kesehatan di pusat kesehatan masyarakat, balai kesehatan, rumah sakit dengan sasaran pasien dan keluarga pasien, 3 . Pendidikan kesehatan ditempat-tempat kerja dengan sasaran buruh atau karyawan.

Berdasarkan dimensi tingkat pelayanan kesehatan, pendidikan kesehatan dapat dibagi: 1. Promosi kesehatan (health promotion) yaitu peningkatanderajad atau setatuskesehatanmasyarakatyang dilakukan melalui pendidikan, penyuluhan ataupun pelatihan kesehatan, 2. Perlindungan umum dan khusus (general and specific protection) yaitu usaha untuk melindungi masyarakat untuk memberikan perlindungan ataupun pencegahan terhadap terjangkitnya suatu penyakit contohnya dengan program imunisasi, 3. Diagnosis dini dan pengobatan segera (early diagnosis and prompt treatment) yaitu suatu usaha awal untuk mendeteksi suatu penyakit akibat rendahnya pengetahuan dan kesadaran masyarakat terhadap kesehatan dan penyakit, 4. Pembatasan kecacatan (disability limitation) yaitu suatu usaha mencegah terjadinya kecacatan akibat pengobatan yang kurang tuntas akibat ketidak tahuan masyarakat atau menganggap bahwa penyakitnya sudah sembuh, dan 5. Rehabitasi (rehabitation) yaitu suatu usaha untuk memulihkan akibat sakit atau cedera yang terkadang orang enggan atau malu untuk melakukannya. 
Saat ini istilah pendidikan kesehatan lebih di kenal dengan istilah promosi kesehatan. Promosi kesehatan merupakan revitalisasi pendidikan kesehatan pada masa lalu. Promosi kesehatan merupakan program kesehatan yang dirancang untuk membawa kebaikan yang berupa perubahan perilaku, baik di dalam masyarakat maupun lingkungan, sedangkan pendidikan kesehatan merupakan pemberian informasi mengenai perubahan perilaku hidup sehat.

\section{Pengertian kesehatan lingkungan}

Kesehatan lingkungan berasal dari dua kata yaitu kesehatan dan lingkungan yang pengertiannya sebagai berikut. Sehat (menurut WHO) adalah suatu keadaan yang baik dari fisik, mental, sosial dan bukan hanya terhindar dari penyakit atau. Lingkungan adalah sesuatu yang berada di alam sekitar baik berupa bahan, kekuatan, kehidupan, maupun zat yang memiliki potensi menyebabkan penyakit. Kesehatan lingkungan pada hakekatnya adalah sesuatu kondisi atau keadaan lingkungan yang optimum sehingga berpengaruh positif terhadap terwujudnya status kesehatan yang optimum pula. Kesehatan lingkungan adalah suatu keseimbangan ekologis yang harus ada antara manisia dengan lingkungannya agar dapat menjamin keadaan sehat dari manusia. Kesehatan lingkungan menurut himpunan ahli kesehatan lingkungan adalah suatu kondi lingkungan yang mampu menopang keseimbangan ekologis yang dinamis antara manusia dan lingkungan untuk mendukung tercapainya realitas hidup manusia yang sehat, sejahtera dan bahagia. Kesehatan lingkungan adalah upaya untuk melindungi kesehatan manusia melalui pengelolaan pengawasan dan pencegahan faktor-faktor lingkungan yang dapat mengganggu kesehatan manusia.

Menurut July Soemirat tahun (2011), kesehatan lingkungan dapat diartikan sebagai ilmu yang mempelajari interaksi antara lingkungan dengan kesehatan manusia, tumbuhan, dan hewan dengan tujuan untuk meningkatkan faktor lingkungan yang menguntungkan (eugenik) dan mengendalikan faktor yang merugikan (disgenik), sedemikian rupa sehingga resiko terjadinya gangguan kesehatan dan keselamatan jadi terkendali. Kesehatan lingkungan adalah ilmu dan seni untuk mencegah pengganggu menanggulagi kerusakan dan meningkatkan/memulihkan fungsi lingkungan melalui pengelolaan unsur-unsur/faktor-faktor lingkungan yang beresiko terhadap 
kesehatan manusia dengan cara identifikasi, analisis, interfensi/ rekayasa, sehingga tersedianya lingkungan yang menjamin bagi derajad kesehatan manusia secara optimal. Ilmu kesehatan lingkungan diberi batasan sebagai ilmu yang mempelajari dinamika hubungan interaktif antara kelompok penduduk atau masyarakat dengan segala macam perubahan komponen lingkungan hidup seperti spesies kehidupan, bahan, zat atau kekuatan di sekitar manusia, yang menimbulkan ancaman, atau berpotensi menimbulkan gangguan kesehatan masyarakat, serta mencari upaya-upaya pencegahan (Umar Fahmi Achmadi 1991).

Dengan demikian kesehatan lingkungan adalah keseimbangan dalam ekologis terhadap berbagai masalah kesehatan sebagai akibat dari hubangan interaktif antara berbagai bahan, kekuatan, kehidupan, dan zat yang memiliki potensi penyebab sakit yang timbul akibat adanya perubahan lingkungan dengan masyarakat, serta menerapkan upaya pencegahan gangguan kesehatan yang ditimbulkannnya. Kesehatan lingkungan merupakan faktor penting dalam kehidupan sosial kemasyaratan, bahkan merupakan salah satu unsur penentuan dalam kesejahteraan penduduk. Lingkungan yang sehat sangat dibutuhkan bukan hanya untuk meningkatkan derajat kesehatan masyarkat, tetapi juga untuk kenyamanan hidup dan meningkatkan efisiensi kerja dan belajar.

\section{E. Ruang Lingkup Kesehatan Lingkungan}

Menurut WHO ada 17 ruang lingkup kesehatan lingkungan, antara lain: 1) Penyediaan air minum, 2) Pengelolaan air buangan dan pengendalian pencemaran, 3) Pembuangan sampah padat, 4) Pengendalian vektor, 5) Pencegahan/pengendalian pencemaran tanah oleh ekskreta manusia, 6) Higiene makanan termasuk higiene susu, 7) Pengendalian pencemaran udara, 8) Pengendalian radiasi, 9) Kesehatan kerja, 10) Pengendalian kebisingan, 11) Perumahan dan pemukiman, 12) Aspek kesehatan lingkungan dan trasportasi udara, 13) Perencanaan daerah dan perkotaan, 14) Pencegahan kecelakaan, 15) Rekreasi umum dan periwisata, 16) Tidakan-tindakan sanitasi yang berhubungan dengan keadaan epidemi/wabah, bencana alam dan perpindahan penduduk, 17) Tindakan pencegahan yang di perlukan untuk menjamin lingkungan. Menurut Pasal 22 ayat 3 Undang-undang Nomor 23 Tahun 1992, ruang lingkup kesehatan 
lingkungan: 1) Penyehatan air dan udara, 2) Pengamanan limbah padat/sampah, 3) Pengamanan limbah cair, 4) Pengamanan limbah gas, 5) Pengamanan radiasi, 6) Pengamanan kebisingan, 7) Pengaman vektor penyakit, 8) Penyehatan dan pengamanan lainnya: misalnya pasca bencana.

\section{Penyediaan air minum}

Air minum merupakan salah satu kebutuhan dasar bagi kualitas dan keberlanjutan kehidupan manusia. Oleh karenanya air minum mutlak harus tersedia dalam kualitas dan kuantitas yang memadai. Untuk memenuhi kebutuhan dasar tersebut diperlukan sistem penyediaan air minum yang berkualitas, sehat, efisien, dan efektif, terintregasi dengan sektor-sektor lainnya terutama sektor sanitasi, sehingga masyarakat dapat hidup sehat dan produktif. Sumber-sumber air minum pada umumnya dan di daerah pedesaan khususnya tidak terlindung sehingga air tersebut tidak atau kurang memenuhi persyaratan kesehatan. Untukitu perlu pengolahan terlebih dahulu. Agar air minum tidak menyebabkan penyakit, maka air tersebut hendaknya diusahakan memenuhi persyaratan-persyaratan kesehatan, setidaknya diusahakan mendekati persyaratan tersebut. Air yang sehat menurut Notoatmodjo (2003) harus mempunyai persyaratan sebagai berikut:

a. syarat fisik; persyaratan fisik untuk air minum yang sehat adalah bening (tak berwarna), tidak berasa, tidak berbau, suhu antara 10$25^{\circ} \mathrm{C}$ dan tidak meninggalkan endapan. Cara mengenal air yang memenuhi persyaratan fisik ini dapat dengan mudah diamati.

b. syarat bakteriologis; air untuk keperluan minum yang sehat harus bebas dari segala bakteri, terutama bakteri patogen. Cara untuk mengetahui apakah air minum terkontaminasi oleh bakteri patogen adalah dengan memeriksa sampel (contoh) air tersebut.

c. syarat kimia; air minum yang sehat harus mengandung zat-zat tertentu di dalam jumlah yang tertentu pula, tidak mengandung bahan kimiawi yang mengandung racun, tidak mengandung zatzat kimiawi yang berlebihan, cukup yodium, $\mathrm{pH}$ air antara 6,5 9,2. Kekurangan atau kelebihan salah satu zat kimia di dalam air akan menyebabkan gangguan fisiologis pada manusia. 
d. syarat radiologi; konduktivitas atau daya hantar, pesistivitas, dan PTT atau TDS (kemampuan air bersih untuk menghantarkan arus listrik).

Penyediaan air harus memenuhi kuantitas dan kualitas, yaitu: aman dan higienis, baik dan layak minum, tersedia dalam jumlah yang cukup, dan harganya relatif murah atau terjangkau oleh sebagian besar masyarakat. Batasan-batasan penyediaan air yang bersih dan aman, antara lain: bebas dan kontaminasi kuman atau bibit penyakit , bebas dari substansi kimia yang berbahaya dan beracun, tidak berasa dan tidak berbau, dapat digunakan untuk mencukupi kebutuhan domestik dan rumahtangga, serta memenuhi standar minimal yang ditentukan oleh WHO atau Departemen Kesehatan RI.

\section{Pengendalian pencemaran udara}

Pencemaran udara adalah kondisi udara yang tercemar dengan adanya bahan, zat-zat asing atau komponen lain di udara yang menyebabkan berubahnya tatanan udara oleh kegiatan manusia atau oleh proses alam, sehingga kualitas udara menjadi kurang atau tidak dapat berfungsi lagi sesuai dengan peruntukannya. Pencemaran udara mempengaruhi sistem kehidupan makhluk hidup seperti gangguan kesehatan, ekosistem yang berkaitan dengan manusia. Pencemaran udara dibedakan menjadi pencemaran primer dan pencemaran sekunder. Pencemaran primer adalah subtansi pencemaran yang ditimbulkan langsung dari sumber pencemaran udara. Karbon monoksida adalah sebuah contoh dari pencemaran udara primer karena ia merupakan hasil dari pembakaran. Pencemaran sekunder adalah subtansi pencemar yang terbentuk dari reaksi pencemarpencemar primer di atmofer. Sumber pencemaran udara akibat kegiatan manusia antara lain: transportasi, industri, pembangkit listrik, pembakaran (perapian, kompor dan berbagai jenis bahan bakar) gas buangan pabrik yang menghasilkan gas berbahaya seperti (CFC). Sumber pencemaran udara alami antara lain: gunung berapi, kebakaran hutan, dan denitrifikasi biologi. Pengendalian pencemaran udara dapat dilakukan dengan dua cara: yaitu pengendalian pada sumber pencemaran dan pengeceran limbah gas. Pengendalian pada sumber pencemaran merupakan metode yang lebih efektif, karena hal tersebut dapat mengurangi keseluruhan limbah gas yang akan diproses dan yang pada akhirnya dibuang ke lingkungan. Di dalam 
sebuah pabrik kimia, pengendalian pencemaran udara terdiri dari dua bagian yaitu penanggulangan emisi debu dan penanggulangan emisi senyawa pencemar.

\section{F. Tujuan pemeliharaan kesehatan lingkungan}

Tujuan pemeliharaan kesehatan lingkungan menurut Sumantri (2010) adalah:

1. Melakukan koreksi atau perbaikan

Terhadap segala bahaya dan ancaman pada kesehatan dan kesejahteraan hidup manusia.

2. Melakukan usaha pencegahan

Dengan cara mengatur sumber-sumber lingkungan dalam usaha meningkatkan derajat kesehatan dan kesejahteraan hidup manusia.

3. Melakukan kerjasama dan menerapkan program terpadu

Diantara masyarakat dan institusi pemerintah serta lembaga non pemerintah dalam menghadapi bencana alam atau wabah penyakit.

4. Mengurangi pemanasan global

Dengan menanam tumbuhan sebanyak-banyaknya pada lahan kosong, maka kita juga ikut serta mengurangi pemanasan global, karbon, zat $\mathrm{O} 2$ (oksigen) yang dihasilkan tumbuh-tumbuhan dan zat tidak langsung zat CO2 (carbon) yang menyebabkan atmosfir bumi berlubang ini terhisap oleh tumbuhan dan secara langsung zat $\mathrm{O} 2$ yang dihasilkan tersebut dapat dinikmati oleh manusia tersebut untuk bernafas.

5. Menjaga kebersihan lingkungan

Agar lingkungan sehat maka harus dijaga kebersihannya, karena lingkungan yang sehat adalah lingkungan yang bersih dari segala penyakit dan sampah. 


\section{DAFTAR PUSTAKA}

Efendi, Feri. 2009. Keperawatan kesehatan komunitas. Jakarta: Salemba Medika.

Herawati, dkk. 2001. Pendidikan kesehatan dalam keperawatan, Jakarta: EGC

Juli Soemirat, 2011. Kesehatan lingkungan. Yogyakarta: Gadjah Mada University Press

Notoatmodjo, Soekidjo, 1993.Pengantar pendidikan dan prilaku kesehatan. Yogyakarta: Andi Offset.

Umar Fahmi Achmadi. 1991. Transformasi kesehatan lingkungan dan kesehatan kerja di Indonesia. Jakarta: UI Press

Wahid dkk. 2007. Promosi kesehatan. Yogyakarta: Graha ilmu 
Bintoro Widodo - Pendidikan Kesehatan dan Aplikasinya... 